\begin{tabular}{|c|ccc|c|}
\hline & PORT SAID ENGINEERING RESEARCH JOURNAL \\
\hline
\end{tabular}

\title{
Refloating Scenarios of an Intact Stranded Tanker
}

\begin{abstract}
In most grounding casualties, rapid refloating is desirable to remove the ship from a place of danger, to reduce stress in the hull and to minimize the risk of pollution. Different grounding conditions have been attributed to a candidate double hull tanker in order to investigate the possible refloating scenarios of the intact-grounded vessel. The refloating operation may consist of lightening and/or internal weight transfer. The objective of this paper is to illustrate an efficient weight management technique that may help the shipmaster to attain a good refloating procedure. For this purpose, each situation is analyzed; stability and strength check are made in order to depict the safe action to be undertaken. The results are graphically represented to make them of practical use for the operator. It is recommended that the resulting graphs are prepared in the design stage as a kind of Risk Management Solution, which helps the shipmaster to take quick, right and at the same time cost-efficient decision.
\end{abstract}

Keywords: salvage, refloating, double hull tanker, stranded, risk management

\section{Nomenclature}

$\begin{array}{ll}\text { d }_{\text {pin }} & \text { : Depth above pinnacle } \\ \mathbf{D}_{\mathbf{w t}} & \text { : Deadweight } \\ \text { GR/W } & \text { : Ground reaction to ship weight ratio } \\ \text { GM }_{\mathbf{T}} & \text { : Metacentric height } \\ \text { L.B.P. } & \text { : Length between Perpendiculars } \\ \text { L.C.R. } & \text { : Longitudinal Center of Reaction } \\ \text { L.O.A. } & \text { : Length Overall } \\ \text { m-AP } & \text { : Distance from Aft Perpendicular } \\ \text { m-CL } & \text { : Distance from centerline } \\ \text { RM } & \text { : Righting moment } \\ \text { R.M.G. } & \text { : Righting Moment Gu ide } \\ \text { T } & \text { : Design ship draft } \\ \text { T.C.R. } & \text { : Transverse center of reaction } \\ \text { B } & \text { : the ratio of the maximu m bending } \\ & \text { mo ment to the allowable bending mo ment }\end{array}$

\section{Introduction}

A grounding ship is in a position not intended by her designers, builders, or operators. No matter how secure a stranded ship may appear, she is in a dangerous position because she is subject to very different forces and conditions than when in normal service. In most cases, rapid refloating is desirable to remove the ship from a place of danger, to reduce stress in the hull, and to decrease the risk of pollution. Pressure for immediate action must not cloud good judgment. The fundamental goal is safe refloating of the stranded ship. Action taken by ship captain in haste can hazard the ship, complicate the refloating operation, or de lay its completion.

Knowledge and experience with vessel casualties is not widespread in the marine industry. Most mariners go through their entire careers without experiencing a major casualty. The modern approach to safety of seaborne

${ }^{1}$ M.Sc. in Naval Architecture and Marine Engineering, General Authority of Port-Said Ports, Egypt

${ }^{2}$ Department of Naval Architecture and Marine Engineering, Faculty of Engineering, Port-Said University, Egypt transportation requires applying the so-called life-circle approach by integrating the design for safety, safe operation and safe salvage methods. Most of the salvage activities have been associated with using the rules of thumb without a support based on the safety assessment process. The effective and safe ship salvage requires developing the methods, models, and tools for the assessment of risk and safety of ships in damaged conditions.

Picolo et al. presented the main technical aspects related to salvage operations [1]. Examples and case studies were included and new research areas indicated. The authors developed various techniques for the scientific treatment of the operations of refloating vessels and pointed out the need to extend these developments with the inclusion of experimental tests that validate numerical applications.

Varsami et al. studied refloating a bulk carrier ship using the main engine in different levels and directions of speed with ballasting/de-ballasting the ship in order to reduce the bow draft and thus the pressure exerted by the ship on the sea bottom [2]. The authors concluded that the method used to refloat the ship did not succeed to free her. They recommended future research that take into consideration to move the cargo from the forward tanks to another ship and eventually to ask for external help. The objective of this work is to study refloating of grounded tanker ship using weight lightening and internal weight transfer. The usual weight transfer is done from cargo tanks to cargo tanks, which requires the ship to be partially loaded. In this paper, new technique is presented and studied, from stability and strength point of views, to transfer cargo from cargo tank to ballast tank when she is fully loaded. The proposed technique help the captain of a grounded ship in specific situations to proceed with the refloating even before the intervention of external help. The recommendations are influenced by tanks capacity, 
ship bending moment, and the facilities available onboard ship.

\section{Refloating of Stranded Ships}

Refloating operations of grounded tankers often may require the shifting of weight, usually by internal and or external cargo transfer. Some examples of actual successful salvage operations worldwide are summarized in Table 1.

Table 1: Actual Refloating Operations

\begin{tabular}{|l|l|}
\hline \multicolumn{1}{|c|}{$\begin{array}{c}\text { Ship Name } \\
\text { (Grounding Date) }\end{array}$} & \multicolumn{1}{c|}{ Reported information } \\
\hline $\begin{array}{l}\text { Nanny [3] } \\
1 / 12 / 2010\end{array}$ & $\begin{array}{l}\text { Almost 1.3 million gallons were transferred } \\
\text { into lightering vessel. } \\
\text { Refloated on 15/12/2010 }\end{array}$ \\
\hline $\begin{array}{l}\text { Sichem Osprey [4] } \\
10 / 2 / 2010\end{array}$ & $\begin{array}{l}\text { Use of tugs and nearly 40\% of the weight } \\
\text { of the cargo was pumped out. } \\
\text { Refloated on 7/3/2010 }\end{array}$ \\
\hline $\begin{array}{l}\text { Yasa Golden } \\
\text { Dardanelles[5] } \\
20 / 2 / 2009\end{array}$ & $\begin{array}{l}\text { Transfer of } 83,800 \text { barrels of product into } \\
\text { lightering vessel.Refloated on 23/2/2009 }\end{array}$ \\
\hline $\begin{array}{l}\text { White Sea[6] } \\
7 / 2007\end{array}$ & Transfer of product into lightering vessel. \\
\hline $\begin{array}{l}\text { Aleksandr } \\
\text { Pokryshkin[6] } \\
5 / 2004\end{array}$ & $\begin{array}{l}\text { Transfer of 6,000 metric tons of fuel oil } \\
\text { from the casualty. }\end{array}$ \\
\hline
\end{tabular}

To refloat most large ships and many small ones, it is necessary to reduce the ground reaction so that the freeing force will be within the capacity of the pulling system that is practical to employ. In some cases, such as those of laden tankers where the ground reaction may be sharply reduced by removing cargo, it is possible to refloat the ship by ground reaction reduction alone. In other cases, a combination of ground reaction reduction and pulling is used. Ground reaction should be reduced as much as practical to minimize damage from dragging the ship with her bottom in contact with the seafloor.

Figure 1 summarizes the methods mostly adopted to refloat stranded ships as explained in U.S. Salvage Manual[7]. Weight management is a widely used technique. It includes determination of the effects of weight on stability and hull strength, removal or redistribution of weight to reduce ground reaction, and temporary replacement of weight to hold the ship

on her strand until a refloating effort is ready. Weight changes must be carefully planned, and their effects should be determined before changes are made. In most stranding conditions, the effects of weight changes on stability and hull strength will limit the changes that can be made. Refloating a grounded tanker often requires the shifting of weight, usually by cargo transfer, either internal or external cargo transfer. In fact, this will always be the case unless the vessel grounded at low speed and can be pulled free, or a rising tide can be used to advantage.

Internal cargo transfer may be effective if a modest change in trim is sufficient to refloat the vessel. External cargo transfer is required if a more radical change in trim or draft is necessary. Internal transfer often can be conducted with liquid cargoes without outside assistance, while external transfer requires other ships or barges and ship-to-ship lightering equipment. Usually, cargo is removed by bringing a receiving or lightering vessel to the casualty site and pumping the casualty's cargo to it [8].

In this paper, both types of cargo transfer are discussed for refloating of stranded double hull tanker to help the ship operator to take a proper salvage decision.

\section{Proposed Techniques for Internal Transfer}

In this method, the ballast water tanks are used as the destination tanks to receive the amount of cargo oil in cargo tanks, in order to reduce the grounding reaction and refloat the ship. The amount of cargo oil to be transferred to ballast tanks would be determined according to the location of the farthest cargo tanks from the pinnacle position, and according to the capacity of ballast tanks.

\subsection{Proposed Technique}

The proposed technique is described by the following steps:

- Determine the stranding condition (grounding reaction, hull girder bending moment, $\mathrm{GM}_{\mathrm{T}}$, heel and trim angles, etc...). 


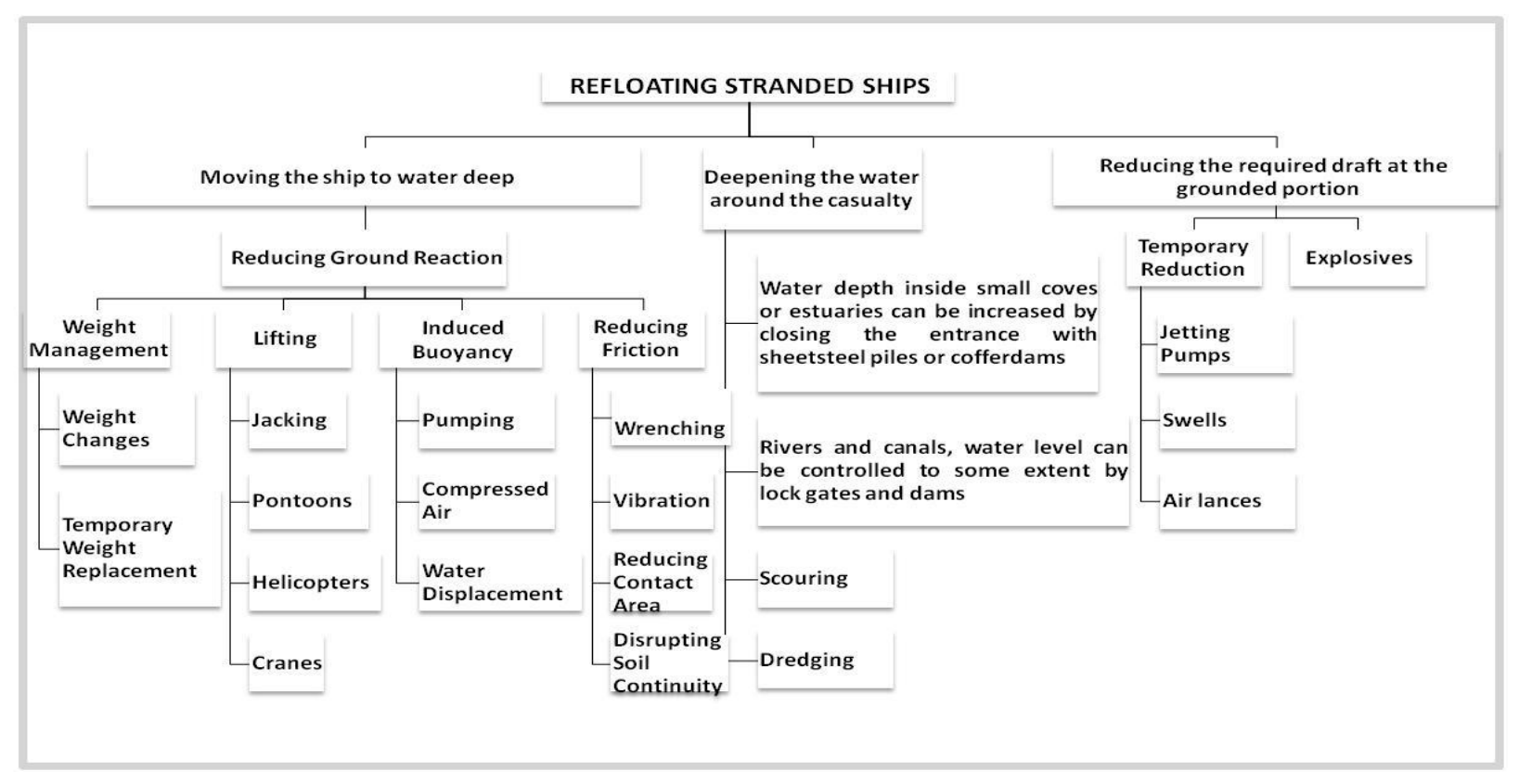

Figure $1:$ Methods of Refloating Stranded Ships

- Determine the limitations to the refloating operation (bending moment limit, limit $\mathrm{GM}_{\mathrm{T}}$,trim angle , heel angle)

- Transfer the cargo oil from cargo oil tanks to isolated ballast water tanks or external vessel.

- After refloating the ship, the cargo oil in isolated ballast tanks may be re-transferred to cargo oil tanks.

\subsection{Required facilities}

The main facilities that may be used to carry out the internal transfer are the following:

\subsubsection{Determination of Isolated ballast tanks}

First, the suitable ballast tanks which may be used as destination tanks which made the ship afloat and made the isolation process on ballast system by install the blind flange on the suction and delivery pipes inside tanks to prevent the contamination of the rest ballast water system by the cargo oil in case not used the installed pumps to discharge the cargo oil from the ballast tanks (if connecting pipes are not used).

\subsubsection{Selection of adequate pumps}

The pumps used to transfer the amount of cargo oil from the cargo tanks to isolated ballast tanks may be selected from the following available facilities:

\section{- Installed pumps}

The ship's installed cargo handling systems provide the fastest and safest method of cargo transfer. It is most practical to transfer cargo with installed systems when the casualty is intact. During the discharge of cargo from ballast tanks, the use of the emergency connection between the ballast water system and cargo pump may be used. The connection pipe shall be provided with a removable spool piece and a closing valve and non-return valve in series in the suction side to the cargo oil pump [9].

- $\quad$ Hydraulic submersible pumps
The hydraulic submersible pump is specifically designed to pump oil from ship. The size and capacity of the pump make it especially suitable for offloading tankers.

\section{- $\quad$ Pneumatic double-diaphragm pumps}

These are excellent machines for pumping fuel from casualties. These positive displacement pumps are simple, reliable, quiet, and suitable for liquids of all viscosities and present no explosion hazard.

- External hoses and manifold

Additional hoses may be requested to discharge the cargo oil from cargo manifold to opened manhole of isolated ballast tanks on the main deck. Cargo transfer through hose strings tailored to the particular circumstances of the operation. Hose strings must be long enough to accommodate the changes that will occur during the transfer and must be of diameter compatible to the cargo manifold valves. Commonly, there are two strings of 0.1 to $0.3 \mathrm{~m}$ hose, long enough to handle all vertical and horizontal movements. Hoses and as sociated hardware compatible with the installed system and cargo are usually found aboard the casualty. If this equipment is not acceptable, hose and fittings may be brought to the scene.

\subsubsection{Inert gas system}

To decrease the risk of fires and explosions during cargo transfer, the space above the cargo is filled with inert gas. The inert gas systems will be supplied from the boiler or engine of the ship.

\subsubsection{Heating system for ballast water tanks}

If the cargo oil in ballast water tank requires heat to rise its temperature for easy pumping, available heating coils can be used such as submersible heating coil that connects in-line with the steam hose coming from the main boiler of the ship.

3.2.5. Crude oil washing for ballast water tanks 
After refloating operation and pumping out of cargo oil from isolated ballast tanks to cargo tanks, the tanks must be washed and cleaned from the cargo oil.

\section{Candidate Double Hull Tanker}

In this study, virtual scenarios are generated to study the possible solutions for refloating of a stranded doublehull tanker, referred here as Tanker (A), having the following particulars:

$\begin{array}{rr}\text { L.O.A. } & 280 \mathrm{~m} \\ \text { L.B.P. } & 264 \mathrm{~m} \\ \text { Breadth } & 48 \mathrm{~m} \\ \text { Depth } & 24 \mathrm{~m}\end{array}$

The typical configuration of the double-hull tanker having an "L" ballast tank arrangement is shown in Figure 2. This ship is a sample vessel modeled by Herbert Engineering Software (HECSALV) [10]; data of this ship including hull and compartment geometry, lightship weight distribution and structural section properties is provided. The study assumes the tanker with $95 \%$ full loading condition is crossing Suez Canal and having an even keel at draft $16.5 \mathrm{~m}$ before stranding.

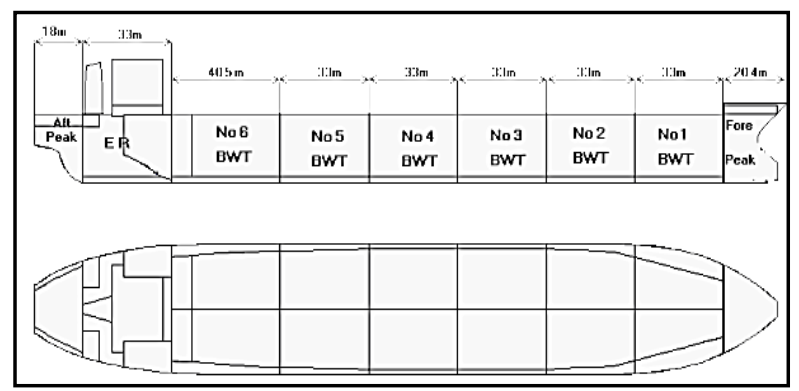

Figure 2 : Sheer Plan and Breadth Plan of Tanker (A) [10]

Table 2 gives intact trim and stability information for the ship. For simplification, Tanker (A) is assumed to remain intact, with no deflection, no residual stress, and no corrosive damage. The data generation starts by setting the governing factors for each situation [11]; for instance, the stranded ship factors required are related to the type of contact, which is assumed in the present study to be one mud pinnacle, having a coefficient of friction 0.3 .

Table 2: Intact Trim and Stability summary

\begin{tabular}{|c|c|c|c|}
\hline Item & Weight (t) & \multirow{2}{*}{\multicolumn{2}{|c|}{ Stability Calculation }} \\
\hline Light Ship & 22,849 & & \\
\hline Cargo Oil & 149,247 & Static Heel Angle & $0^{\circ}$ \\
\hline \begin{tabular}{|l|} 
Fuel Oil \\
\end{tabular} & 2,256 & $\mathrm{VCG}(\mathrm{m})$ & 13.048 \\
\hline Diesel Oil & 170 & LCG(m from AP $)$ & 139.89 \\
\hline Lube Oil & 66 & TCG( $\mathrm{m}$ from $\mathrm{CL})$ & 0.003 Port \\
\hline Fresh Water & 498 & $\mathrm{KM}_{\mathrm{T}}(\mathrm{m})$ & 19.704 \\
\hline Displacement & \begin{tabular}{l|l}
$\mathrm{t}$ & 175,393
\end{tabular} & $\mathrm{GM}_{\mathrm{T}}(\mathrm{m})$ & 5.095 \\
\hline \multicolumn{2}{|c|}{ Drafts } & \multicolumn{2}{|c|}{ Strength Calculation } \\
\hline AP & $16.591 \mathrm{~m}$ & Shear force $(\mathrm{T})$ & $\begin{array}{l}6,136 \\
(218 \mathrm{~m} \text { from } \mathrm{AP})\end{array}$ \\
\hline FP & $16.421 \mathrm{~m}$ & $\begin{array}{l}\begin{array}{l}\text { Bending moment } \\
(\mathrm{m} . \mathrm{T})\end{array}\end{array}$ & $\begin{array}{l}420,099 \text { sagging } \\
(135.5 \mathrm{~m} \text { from } \mathrm{AP})\end{array}$ \\
\hline Amidships & $16.506 \mathrm{~m}$ & Shear Allowable & $\begin{array}{l}34 \% \\
\text { (at } 218 \mathrm{~m} \text { from } \mathrm{AP})\end{array}$ \\
\hline Trim & $0.17 \mathrm{~m}(\mathrm{Aft})$ & Bending Moment & $\begin{array}{l}44 \% \\
(135.5 \mathrm{~m} \text { from AP) }\end{array}$ \\
\hline
\end{tabular}

\begin{tabular}{|l|l|l|l|}
\hline & & Allowable & \\
\hline
\end{tabular}

Different grounding scenarios are assumed by varying the longitudinal position of the pinnacle reaction (L.C.R), its transverse position (T.C.R) and height of water above the pinnacle $\left(\mathrm{d}_{\text {pin }}\right)$ as in

Figure 3.Table 3 gives the symbol attributed to each scenario. To refloat the ship there are two options; weight removal and weight transfer. The next sections will analyze the two options from strength point of view.

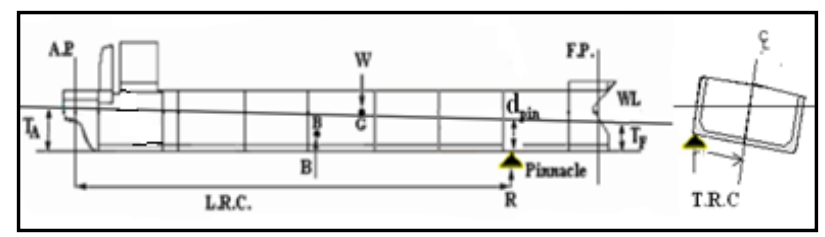

Figure 3: Stranding Positions

Table 3 : Values of Hypothetical Water Depth $\left(\mathrm{d}_{\text {pin }}\right)$

\begin{tabular}{ccc}
\hline Case & $\mathrm{d}_{\text {pin }}(\mathrm{m})$ & $\mathrm{d}_{\text {pin }} / \mathrm{T}(\%)$ \\
\hline $\mathrm{A}$ & 15 & 0.90 \\
\hline $\mathrm{B}$ & 13 & 0.78 \\
\hline $\mathrm{C}$ & 11 & 0.66 \\
\hline $\mathrm{D}$ & 9 & 0.54 \\
\hline $\mathrm{E}$ & 7 & 0.42 \\
\hline $\mathrm{F}$ & 5 & 0.30 \\
\hline $\mathrm{G}$ & 3 & 0.18 \\
\hline
\end{tabular}

\section{Stability afte $\mathbf{r}$ Stranding}

Before we proceed to refloating the ship, it is important to assure that the ship has enough stability after being stranded. After stranding, the ground reaction causes a virtual rise in center of gravity and the ship may be unstable. The ground reaction acts like an upward force (a negative weight). From Figure 4, it can be concluded that if the pinnacle is located at the centerline, the ground reaction is relatively large for different scenarios reported, especially for small values of $d_{\text {pin }}$. One can see Figure 4 that the GR is more than $60 \%$ of the ship weight when $d_{\text {pin }}$ $=3 \mathrm{~m}$ (case $\mathrm{G}$ ). While when the pinnacle is located $23 \mathrm{~m}$ to port away from the centerline, the ground reaction did not exceed $10 \%$ of the ship weight.

Figure 5 shows that as the pinnacle is located at the centerline there is possible hazard related to transverse stability (negative $\mathrm{GM}_{\mathrm{T}}$ ) specially when the height of water above pinnacle is low [11].Figure 6 shows that when the transverse position of the pinnacle is $23 \mathrm{~m}$ away from the centerline, the $\mathrm{GM}_{\mathrm{T}}$ is positive for all the cases. 


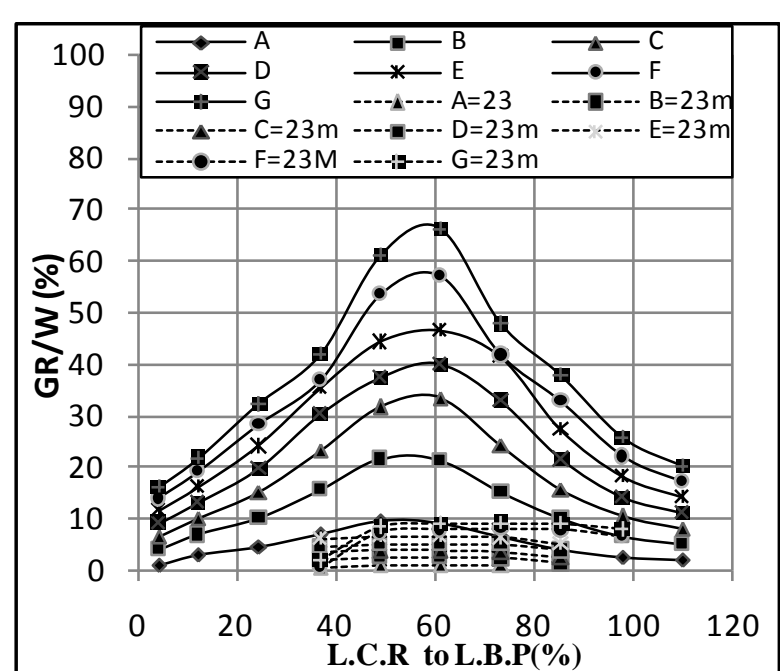

Figure 4: Ground Reaction/ Ship Weight (GR/W) at T.C.R. $=0 \mathrm{~m}$ and $23 \mathrm{~m}$

It is to be noted that if the ship is stable before refloating, she will become more stable during the refloating process and would be stable when afloat. If the ship has a negative $\left(\mathrm{GM}_{\mathrm{T}}\right)$ while aground, she may either become more stable as the ground reaction is reduced and refloat in a stable condition, or refloat in an unstable condition [7]. In the first condition, the ship must be refloated quickly in order to pass from the unstable to the stable condition as rapidly as possible. Ships should not be refloated when they are unstable except in cases of extreme emergency, because there is a high risk of losing the ship or creating a much more difficult salvage situation.

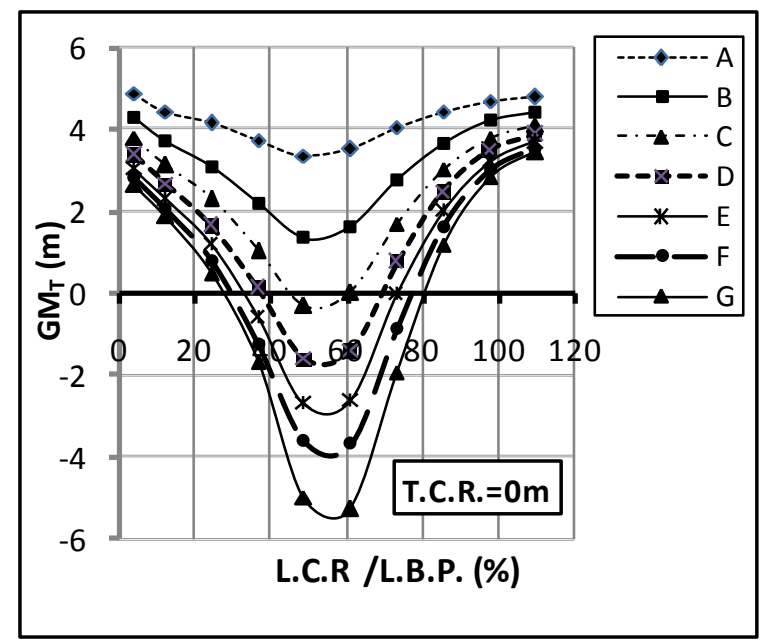

Figure 5 : Metacentric Height at T.C.R. $=0 \mathrm{~m}$ fro $\mathrm{m} \mathrm{CL}$

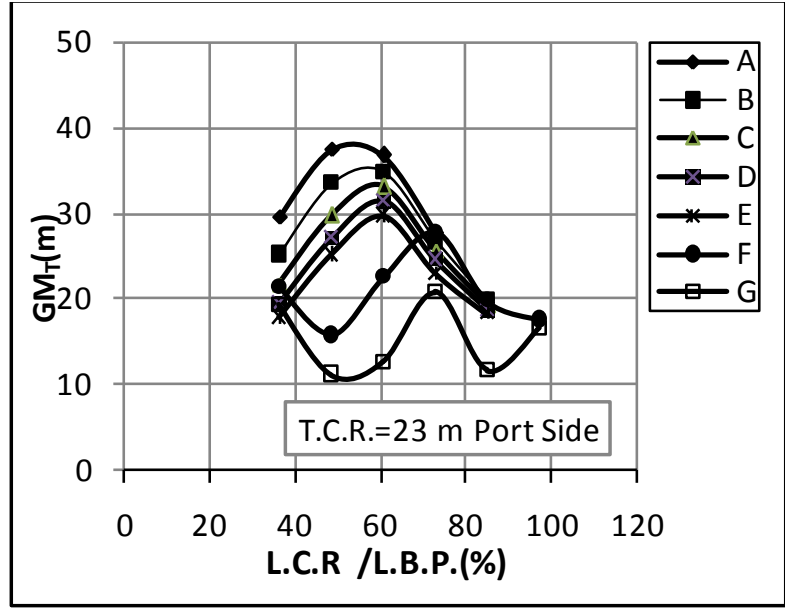

Figure 6: Metacentric Height at T.C.R. $=23 \mathrm{~m}$ fro $\mathrm{m} \mathrm{CL}$

\section{Refloating through Weight Removal}

In this section, refloating the ship is done by weight removal. Removing weight from the grounded ship will force the ship to trim in the opposite direction of the grounding. Removal is done until there is no contact between the ship and the mud pinnacle, consequently, no ground reaction. HECSALV gives ground reaction, $\mathrm{GM}_{\mathrm{T}}$, maximu $\mathrm{m}$ bending moment and the ratio of the maximu $\mathrm{m}$ bending moment to the allowable bending moment. Allowable bending moment is considered at harbor condition which is 1.25 times the allowable bending moment at sea condition as defined in IA CS 2012 [12].

\subsection{Strength Check}

To check the longitudinal strength of the ship, the ratio of the maximum bending moment to the allowable bending moment in the intact condition is calculated in order to assess the situation. The results plotted in Figure 7 show that the worst cases are the stranding conditions C, D, E, $F$ and $G\left(d_{\text {pin }}=3 \sim 11\right)$, if the pinnacle is within the fore or the aft region. It is important to mention that the scenarios showing very high bending moments (as the pinnacle is amidships), are not considered as strength hazard since they are already reported as stability hazard (negative $\mathrm{GM}_{\mathrm{T}}$ ). As the pinnacle is shifted $23 \mathrm{~m}$ fro $\mathrm{m}$ the centerline, the situation is much better from the hull girder point of view, Figure 8. It has been concluded that the most hazardous scenarios to be considered for the study of refloating management are $\mathrm{C}, \mathrm{D}, \mathrm{E}, \mathrm{F}$, and $\mathrm{G}$, where the L.C.R is in the fore region.

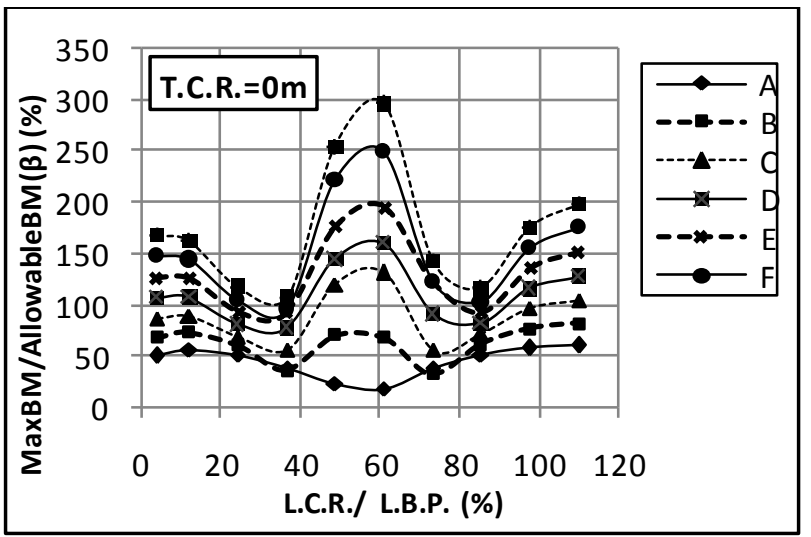

Figure 7: Bending Moment Ratio $(\beta)($ T.C.R. $=0 \mathrm{~m})$ 
The value of the required weight to be removed according to the trim angle is shown in Figure 9, whereas the variation in the longitudinal bending moment is given in Figure 10 . For scenario $\mathrm{G}\left(\mathrm{d}_{\text {pin }}=3\right)$, the reduction of the bending moment ratio from $118 \%$ to $76 \%$ may be achieved by increasing the trim.

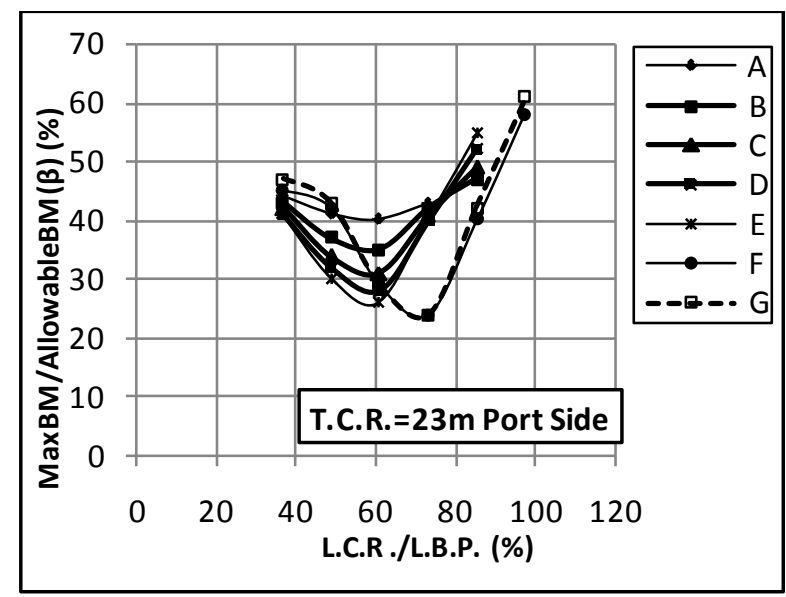

Figure 8: Bending Moment Ratio $(\beta)$ at T .C.R. $=23 \mathrm{~m}$

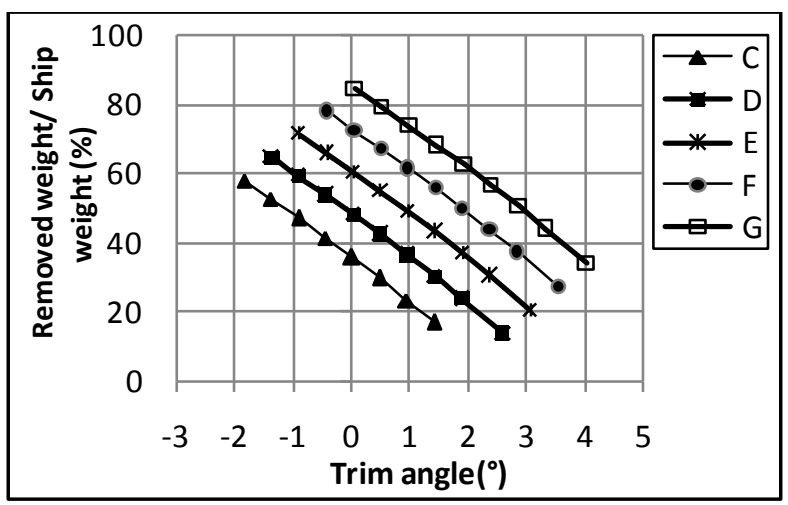

Figure 9 : Weight Removal for Refloating Operation

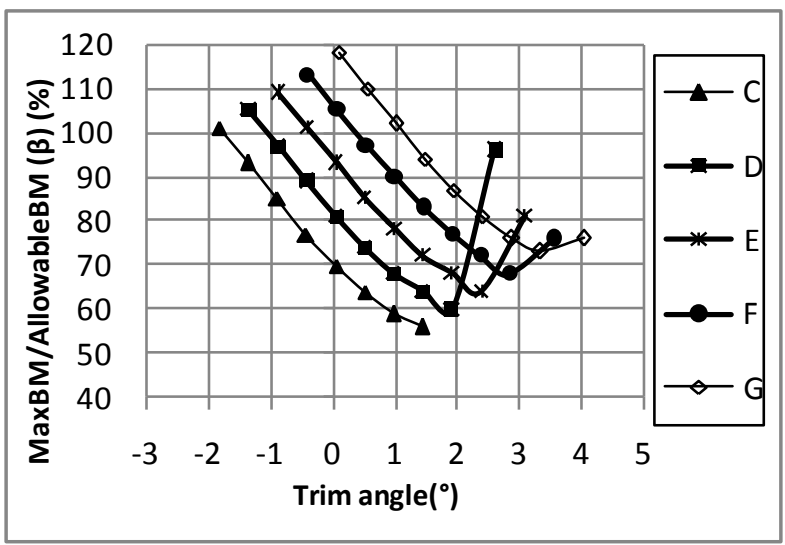

Figure 10: Longitudinal Bending Moment during Refloating

\section{Refloating through Weight Transfer}

In this section, refloating of the stranded ship is supposed to be done by weight transfer using the proposed methods mentioned in section 3. The method depends on transfer weight from cargo tanks to ballast tanks since all cargo tanks are fully loaded. To refloat the ship, weight is transferred from the tanks near the pinnacle to the farthest ballast tank in the opposite direction. The question at this stage is about the amount of oil to be transferred, and its effect on the strength of the ship. The first step is to define the ground reaction and the trim angle. The second step is to define the required righting moment to free the ship; zero ground reaction. For each scenario the maximum bending moment is calculated and then checked $(\beta<100 \%)$.

Figure 11 shows the relation between the vertical position of the pinnacle $\left(\mathrm{d}_{\text {pin }} / \mathrm{T}\right)$ and the required righting moment to free the ship for a given location of the pinnacle; the values attributed to the ratio T.C.R/B that defines the transverse position of the pinnacle are $0.1,0.2,0.3$ and 0.4 respectively; results corresponding to other values may be obtained by interpolation. It is found that if the vertical position of the pinnacle is less than $66 \%$ of the design draft, the ground reaction and the required righting moment to free the ship would be very large. In these cases, transfer cargo to the ballast tanks does not give the required bending moment; consequently, the only option available is weight removal.

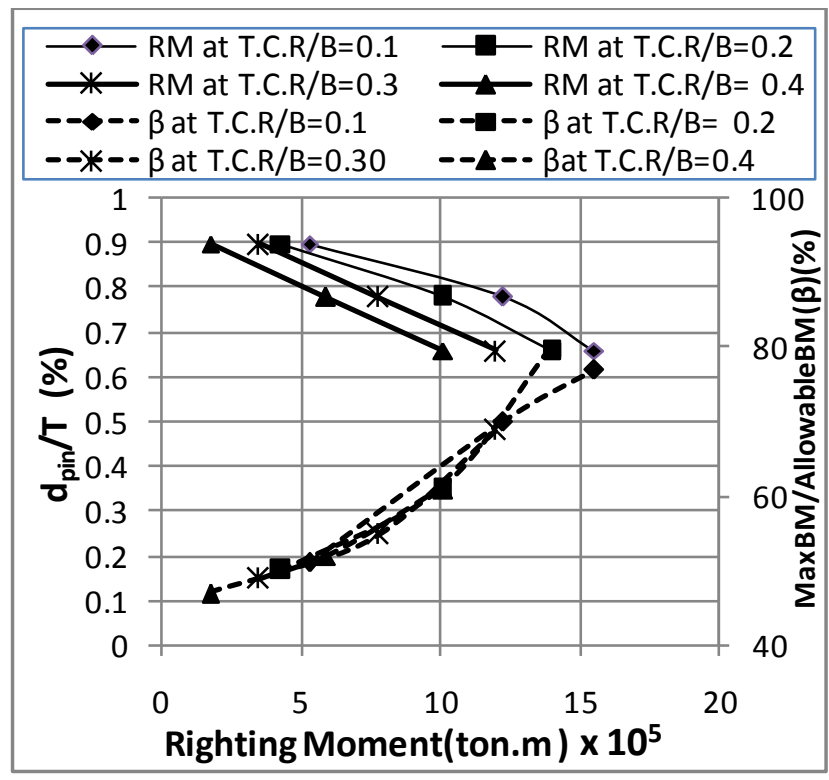

Figure 11: Righting Moment Guide (R.M.G.) for cargo transfer

If value of $\left(\mathrm{d}_{\text {pin }} / \mathrm{T}\right)$ is from 0.9 to $0.66 \%$, the proposed method of transfer cargo oil option can be carried out. Using the upper set of curves in Figure 11, the shipmaster defines the vertical and transverse position of the pinnacle and finds, from the curves, the required righting moment to free the ship:

\section{$\mathrm{RM}=$ Cargo weight $*$ Distance between the two tanks}

Using the lower set of curves, the shipmaster can check the strength of the ship. For the defined righting moment, the corresponding $\beta$ is found to assure that the ship has enough strength during refloating.

Using these sets of curves the shipmaster can make the right refloating decision in short time without any pressure and the complete picture of the situation is available. The main steps of refloating operation are summarized in Figure 12. 


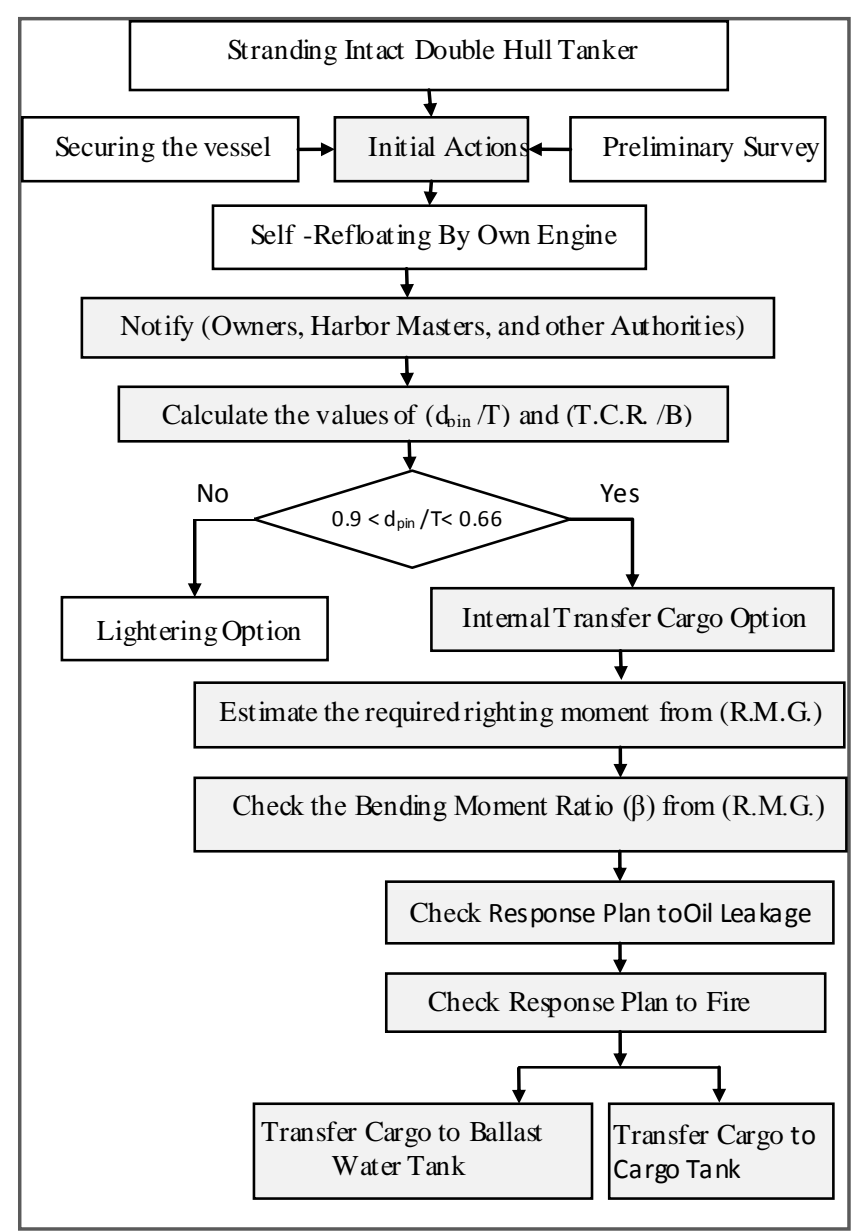

Figure 12: Risk Management during Refloating Stranding Intact Double Hull Tanker

\section{Conclusion}

This work studies the refloating scenarios of an intactgrounded tanker. Many scenarios are assumed varying the longitudinal, transverse, and vertical positions of the pinnacle. The following observations are made:

- High ground reaction is generated when the pinnacle is located at the centerline of the ship and reduced when the pinnacle is away from the centerline.

- When the pinnacle is located transversely at the centerline and longitudinally at $\pm 25 \%$ from the midship, these scenarios are considered as stability hazard as they gave negative $\mathrm{GM}_{\mathrm{T}}$ and are not considered in this study.

- When the pinnacle is away from the centerline, the $\mathrm{GM}_{\mathrm{T}}$ was positive for all the scenarios.

By studying the refloating of the ship by weight removal two set of curves are introduced (Figure 9 and Figure 10); this would help the shipmaster to define the amount of weight to be removed from the ship, and to check the strength during refloating.

The new technique introduced aims to refloat the ship using weight transfer of cargo to ballast tanks in order to reduce the cost of weight removal operation.
A diagram is proposed to determine the righting moment necessary to free the ship. This righting moment is translated to cargo weight and distance between the two tanks.

It is recommended that Figure 9, Figure 10 and Figure 11be prepared in the design stage and delivered to the shipmaster as a kind of "Risk Management" solution, which helps him to make a quick, right, and cost-efficient decision.

\section{Acknowledge ment}

The authors would like to express their gratitude to Herbert Engineering Corporation (HECSALV product) for offering the software license.

\section{References}

[1] Picolo, S., Vasconcellos, J.M: Technical Aspects Of Refloating Operations for Grounded Vessels, COPINA VA L, 2009

[2]Varsami, A., Popescu, C., Hanzu, R., Chircor, M., Refloating a Ship Using Her Own Means, Proceedings of the $23^{\text {rd }}$ International DAAAM Symposium, 23-26th November, Vienna, Austria, Volume 23, No.1, pp. 0263- 0266, 2012

[3]Professional Mariner

http://www.professionalmariner.co m/March-2011/Tankerwith-d iesel-fuel-stranded-for-2-weeks-after-runningaground-in-Northwest-Passage/

[4]Fortunes de Mer

http://www.fortunes mer.com/old/rubriques/liens \%20et \%20contacts/detailsactualites/Sichem Os prey $2010 . \mathrm{htm}$

[5]TITA N Salvage http://www.titansalvage.com/What-We-Do/Responseand-Results

[6]Resolve Marine Group http://www.resolvemarine.co m/job-h is tory.php

[7] NA VSEA (S0300-A6-MAN-010): U.S. Navy Salvage Manual, Volume 1, Stranding and Harbor Clearance, Published By Direction of Commander, Naval Sea Systems Command, 412 pp, 2006

[8]NA VSEA (S0300-A6-MAN-050): U.S. Navy Ship Salvage Manual Volume 5 (Pol Offloading), Published By Direction of Commander, Naval Sea Systems Command, 212 pp, 1991

[9]Det Norske Veritas: rules for classification of, part 5 chapter 3, oil carriers, 68 pp , 2011

[10]Salvage Engineering Software, HECSALV, Herbert Software solutions, Inc. 2011

[11]El-Dessouky, U., Hussein, A., El- Kilani, H.S. and Hegazy, E., Hazard Identification during Refloating of Stranded Intact Double Hull Tanker, Proceeding Black Sea', Vol. 2, 4-6 October, Varna, Bulgaria, 2012

[12]IACS (International Association of Classification Societies), Common Structural Rules for Double Hull Oil Tankers, 2012 